\title{
A RELEVÂNCIA DA CRIAÇÃO DE UMA UNIDADE DE CONSERVAÇÃO NO MORRO GAÚCHO, MUNICÍPIOS DE ARROIO DO MEIO E CAPITÃO/RS
}

\author{
Bruna Letícia Thomas ${ }^{1}$ \\ Pedro Augusto Thomas ${ }^{2}$ \\ Eliane Maria Foleto ${ }^{3}$
}

\begin{abstract}
Resumo: Unidades de Conservação (UCs) são áreas definidas geograficamente vinculadas a processos de gestão de seu território, tendo como objetivo principal a proteção ao longo prazo dos atributos ambientais in situ. Assim, visa-se destacar a importância da criação de uma UC no Morro Gaúcho, patrimônio natural dos municípios de Arroio do Meio e Capitão, Rio Grande do Sul, a partir da identificação dos impactos ambientais que ameaçam a sua biodiversidade e paisagem. Desta forma, o trabalho ocorreu a partir de saídas de campo, leitura de pesquisas já realizadas na área e jornais locais e a participação em reuniões de uma organização não-governamental local. Os impactos ambientais reconhecidos foram a ocorrência de espécies exóticas invasoras, o turismo irregular e a presença de uma unidade de transbordo de resíduos sólidos, entre outros, tendo como consequências as agressões à biodiversidade local. A importância da criação de uma UC no local também é destacada pela presença da Reserva da Biosfera e os percentuais de remanescentes de Mata Atlântica nas áreas dos municípios. Portanto, a instituição de uma área protegida no Morro Gaúcho visa garantir a conservação a partir de uma ação concreta de proteção à natureza e seus processos de manejo e gestão vinculados.
\end{abstract}

Palavras-chave: Unidades de Conservação; Morro Gaúcho; Impactos Ambientais; Proteção.

\section{The importance of creating a conservation unit in Morro Gaúcho, cities of Arroio do Meio and Capitão/RS}

\begin{abstract}
Conservation Units (CUs) are geographically areas defined management processes linked to its territory, having as main objective the protection of long-term environmental attributes in situ. Therefore aims to highlight the importance of creating a UC in Morro Gaucho, natural heritage of the cities of the Arroio do Meio and Capitão, Rio Grande do Sul, from the identification of environmental impacts that threaten its biodiversity and landscape. Thus, the work occurred from field trips, reading research already conducted in the area and local newspapers and attending meetings of a local nongovernmental organization. The environmental impacts were recognized the occurrence of invasive species, tourism and the irregular presence of a unit transshipment of solid waste, among others, with the consequences when the assault on local biodiversity. The importance of creating a UC on site is also highlighted by the presence of the Biosphere Reserve and the percentages of the Atlantic Forest remnants in the areas of the municipalities. Therefore, the establishment of a protected area in Morro Gaúcho aims to ensure the conservation from a concrete action to protect nature and its management processes and management bound.
\end{abstract}

\footnotetext{
${ }^{1}$ Geógrafa, Mestre em Geografia pela Universidade Federal de Santa Maria. E-mail: brunaths@hotmail.com

${ }^{2}$ Acadêmico de Ciências Biológicas. Integrante do Núcleo de Estudos e Pesquisas em Recuperação de Áreas Degradadas da Universidade Federal de Santa Maria - NEPRADE/UFSM. E-mail: pedroathomas@hotmail.com

${ }^{3}$ Professora Doutora do Departamento de Geociências da Universidade Federal de Santa Maria. E-mail: efoleto@gmail.com
} 
Keywords: Conservation Units; Morro Gaúcho; Environmental Impacts; Conservation.

\section{INTRODUÇÃO}

O processo de ocupação e apropriação do solo e seus recursos naturais pela sociedade humana têm ocorrido, na maioria dos casos, de maneira impiedosa e em grande velocidade, fazendo com o que parte da sociedade e do Poder Público passassem a compreender melhor a importância da proteção da natureza.

Uma das formas de buscar o controle de uso sobre espaços que devem ser preservados, conservados e/ou restaurados para assegurar que o equilíbrio ambiental seja mantido, é a criação de áreas protegidas. Essas se tratam de espaços territoriais legalmente protegidos por meio de legislação ambiental específica e visam à proteção e manutenção de locais de relevância física, biológica e cultural. Dentre as áreas protegidas brasileiras existem as Unidades de Conservação (UCs), tanto de âmbito de proteção integral dos atributos ambientais quanto de manejo sustentável.

Deste modo, o presente artigo visa destacar a importância da criação de uma Unidade de Conservação no Morro Gaúcho, patrimônio natural situado nos municípios de Arroio do Meio e Capitão, no estado do Rio Grande do Sul. A criação de uma UC no Morro Gaúcho já foi almejada e debatida no município de Arroio do Meio, mas não obteve êxito. Entretanto esse fato demonstra que parte da população reconhece a relevância da proteção do local, não somente por ser um ponto turístico e visitado na região, mas pelas ameaças que colocam sua biodiversidade e beleza em risco.

\section{UNIDADES DE CONSERVAÇÃO: importantes áreas protegidas}

Uma das políticas de desenvolvimento sustentável e conservação da natureza é a criação de espaços onde se visa à proteção ambiental, denominados de áreas protegidas. Sua implantação tem sido uma das estratégias importantes na contenção de impactos produzidos pelo homem no território e sobre os recursos naturais: "Ela permite a sobrevivência de espaços nos quais os processos de reprodução da biodiversidade e da evolução biológica transcorram sem abalos radicais de origem antrópica" (DRUMMOND; FRANCO; NINIS, 2006, p. 09). Assim, a delimitação de algumas porções do território e limitação de uso de seus recursos tem se tornado uma estratégia relevante de proteção do meio ambiente. 
A IUCN (The International Union for Conservation of Nature - União Internacional para a Conservação da Natureza), importante organização internacional que visa à conservação dos recursos naturais, define o termo áreas protegidas como:

Un espacio geográfico claramente definido, reconocido, dedicado y gestionado, mediante medios legales $u$ otros tipos de medios eficaces para conseguir la conservación a largo plazo de la naturaleza y de sus servicios ecosistémicos y sus valores culturales asociados (DUDLEY, 2008, p. 10).

Trata-se, deste modo, de uma área definida geograficamente vinculada a processos de gestão de seu território, tendo como objetivo principal a proteção ao longo prazo dos atributos ambientais in situ e os benefícios proporcionados.

As áreas protegidas visam à manutenção da biodiversidade, a regulação do clima, o abastecimento de cursos d'água, a garantia de bem estar social, a proteção de lugares de grande beleza, a qualidade de vida e ambiental. Isto é, apresentam a função de manter os recursos naturais e a biodiversidade a partir do estabelecimento de espaços protegidos, nos quais são implantados limites de uso e ocupação segundo instrumentos legais (BENSUSAN, 2006). Braga et al (2008), descrevem estes e outros benefícios oriundos da implementação desses espaços:

As áreas protegidas são importantes tanto do ponto de vista ecológico quanto social, pois mantém a diversidade e a variação genética de espécies dos ecossistemas e dos processos ecológicos essenciais, a beleza cênica do lugar e conservam o estoque de material genético e a quantidade de espécies de fauna e flora economicamente importantes ao homem, tais como: plantas medicinais, recursos alimentícios, entre outras. Esses recursos naturais são também importantes ao bem-estar social, pois podem ser aplicados como alternativas educacionais e recreativas. Além disso, fornecem benefícios para as economias locais e nacionais, por meio do turismo ecológico, produção de medicamentos e rendimentos do uso sustentável dos recursos naturais (BRAGA et al, 2008, p. 78).

Ou seja, essas áreas contribuem para o desenvolvimento do país estimulando o conhecimento científico e ambiental, criando cadeias produtivas de bens e serviços e gerando pólos de desenvolvimento sustentável, que melhoram a qualidade de vida e ambiental da população local e nacional (GURGEL et al., 2011).

No Brasil, existem diferentes tipologias e categorias de áreas protegidas. Essa diversificação é resultante de novos objetivos que foram sendo agregados aos espaços de proteção ambiental, fato que exigiu uma maior flexibilização nas categorias de áreas protegidas, pois 
já que almejavam distintos objetivos, exigiam diferentes formas de manejo (DRUMMOND; FRANCO; NINIS, 2006,).

Aqui, mais especificamente, serão tratadas as Unidades de Conservação (UCs), estabelecidas pela Lei Federal no 9.985/2000 (Sistema Nacional de Unidades de Conservação da Natureza SNUC). Porém, destaca-se que também são áreas protegidas as Áreas de Preservação Permanente - APPs e Reservas Legais (instituídas pelo Código Florestal Brasileiro), Reservas da Biosfera (instituídas pela UNESCO), Terras Indígenas e Quilombolas, Sítios Ramsar, Sítios do Patrimônio da Humanidade, entre outras (MEDEIROS; YOUNG, 2011).

Deste modo, cabe destacar que há muita confusão entre os conceitos áreas protegidas e Unidades de Conservação, sendo entendidos muitas vezes como sinônimos. Porém, ressaltase que toda UC é uma área protegida, mas nem toda área protegida é uma UC. Sendo assim, o art. 2ㅇ da Lei do SNUC conceitua-as como:

Espaço territorial e seus recursos ambientais, incluindo as águas jurisdicionais, com características naturais relevantes, legalmente instituído pelo Poder Público, com objetivos de conservação e limites definidos, sob regime especial de administração, ao qual se aplicam garantias adequadas de proteção (BRASIL, 2000, s/p).

Assim, as UCs produzem espaços de dinâmicas específicas e com uma administração diferenciada, sendo que sua criação é considerada importante estratégia de ordenamento territorial pelo Estado, na medida em que estabelecem limites e restrições para o uso e a ocupação do espaço (MEDEIROS, 2006; MEDEIROS; YOUNG, 2011). Araújo (2007) complementa explicando que essas áreas podem ser entendidas como organizações, visto que se tratam de agrupamentos planejados de pessoas com o propósito de alcançar objetivos que almejam fornecer à população bens e serviços como, por exemplo, a manutenção dos serviços ecossistêmicos, a ciclagem dos nutrientes, o controle de pragas e a polinização.

O SNUC, estabelecido em julho de 2000, é uma política ambiental brasileira com o objetivo de unificar, organizar, planejar e manejar de forma adequada algumas categorias de áreas protegidas brasileiras. Ele estabelece critérios e normas para a criação, implantação e gestão das UCs no âmbito nacional, estadual e municipal a fim de contribuir para o alcance dos objetivos nacionais de conservação (PELLIN et al, 2007). Tais UCs são divididas pelo SNUC em dois grupos distintos, de acordo com seus objetivos e características de manejo: 
Unidades de Proteção Integral: áreas que têm como objetivo preservar a natureza admitindo-se o uso indireto dos recursos naturais em algumas categorias, estando protegidas de grandes interferências humanas. Dentro deste grupo, enquadram-se: Estação Ecológica, Reserva Biológica, Parque Nacional, Monumento Natural e Refúgio da Vida Silvestre. Assim, segundo seus objetivos, as atividades permitidas nas áreas dessas UCs são educação ambiental, visitação, pesquisa científica, turismo e outras que não envolvam a exploração direta de seus recursos.

$\checkmark$ Unidades de Uso Sustentável: áreas que pretendem conciliar a conservação da natureza com o uso sustentável de parte de seus recursos naturais, permitindo-se a exploração desses de forma equilibrada, a fim de garantir sua manutenção ao longo prazo e minimizando os impactos negativos da atuação antrópica. Estão presentes neste grupo as categorias: Área de Proteção Ambiental, Área de Relevante Interesse Ecológico, Floresta Nacional, Reserva Extrativista, Reserva da Fauna, Reserva de Desenvolvimento Sustentável e Reserva Particular do Patrimônio Natural. As atividades previstas para essas são mais variadas: educação ambiental, pesquisa científica, turismo, exploração sustentável de florestas, frutos e sementes, agricultura sustentável, pesca e caça para subsistência, entre outros, sempre visando à garantia de sustentabilidade dos recursos.

Diferentemente de outras áreas protegidas, as UCs necessitam ser criadas por Lei ou Decreto específico para existirem. As APPs, por exemplo, desde que foi criado o Código Florestal, existem em qualquer lugar onde haja a situação de margens de rios, nascentes, topos de morros, declividade acima de 45으, entre outras (BRASIL, 2012). Ou seja, elas já existem por si só, sua proteção é obrigação em todo território nacional. Já as propostas de UCs surgem da necessidade e/ou relevância ambiental de determinado espaço. A partir disso, suas situações serão avaliadas, analisadas, consultadas, suas áreas delimitadas para, então, sua criação ocorrer ou não.

\section{METODOLOGIA}

Este artigo é resultado de pesquisas sobre áreas protegidas que vêm sendo realizadas desde a iniciação científica, em 2009, e recentemente foram aprofundadas para a elaboração da 
dissertação de mestrado, com enfoque para a área de estudo do Morro Gaúcho. Deste modo, os resultados aqui apresentados são decorrentes de leituras acerca das temáticas áreas protegidas, Unidades de Conservação e proteção ambiental em artigos, livros, dissertações, e teses; leituras referentes a legislações ambientais federais, estaduais e municipais; e pesquisas relativas a trabalhos já realizados na área de estudo, o Morro Gaúcho, e nos municípios de Arroio do Meio e Capitão, principalmente relacionados a levantamentos de fauna e flora.

Além disso, trabalhos de campo foram realizados em 2010, 2011 e 2012, visando maior reconhecimento da área de estudo, fato que acabou revelando a presença de ameaças significativas à paisagem do Morro Gaúcho e que reforçam a criação de uma UC no local. As ameaças também foram identificadas a partir de leituras de estudos já desenvolvidos na área (KRÜGER (2008), LEUTCHENBERGER (2005) e ECOBÉ (2004)), notícias de agressões ao objeto de estudo noticiadas em jornais locais e a participação em reuniões da organização não-governamental Ecobé, que luta desde o início dos anos 2000 para a criação de uma UC no morro. Assim, as ameaças identificadas foram descritas e registradas a partir de fotografias.

\section{Localização e situação geográfica da área de estudo}

O Morro Gaúcho, localizado no Vale do Taquari, situa-se na divisa dos municípios de Arroio do Meio e Capitão, Rio Grande do Sul (Figura 1), às margens do rio Taquari. Sua denominação deve-se ao fato de que ao "pé do morro" descansavam os tropeiros, que o tinham como referência. Na época, esse foi denominado Morro dos Gaúchos (KRÜGER, 2008).

Cabe destacar que a denominação "morro" encontra-se mal aplicada à situação desta unidade de relevo. Como o Morro Gaúcho possui uma variabilidade altimétrica de 449 metros (100 metros - base - até 559 metros - pico), este passa a ser considerado uma montanha conforme consta na Resolução no 303 do CONAMA (Conselho Nacional do Meio Ambiente): montanha trata-se de uma "elevação do terreno com cota em relação à base superior à 300 metros" (BRASIL, s/p, 2002). Sartori e Barros Sartori (2004) explicam que montanha é uma grande elevação natural do terreno que constitui formas acidentadas do relevo com a presença de vales profundos, picos e variação altimétrica. 
Entretanto, apesar de "geomorfologicamente incorreto", aqui se utilizará a conceituação "morro", visto que o objeto de estudo assim é regionalmente denominado e conhecido.

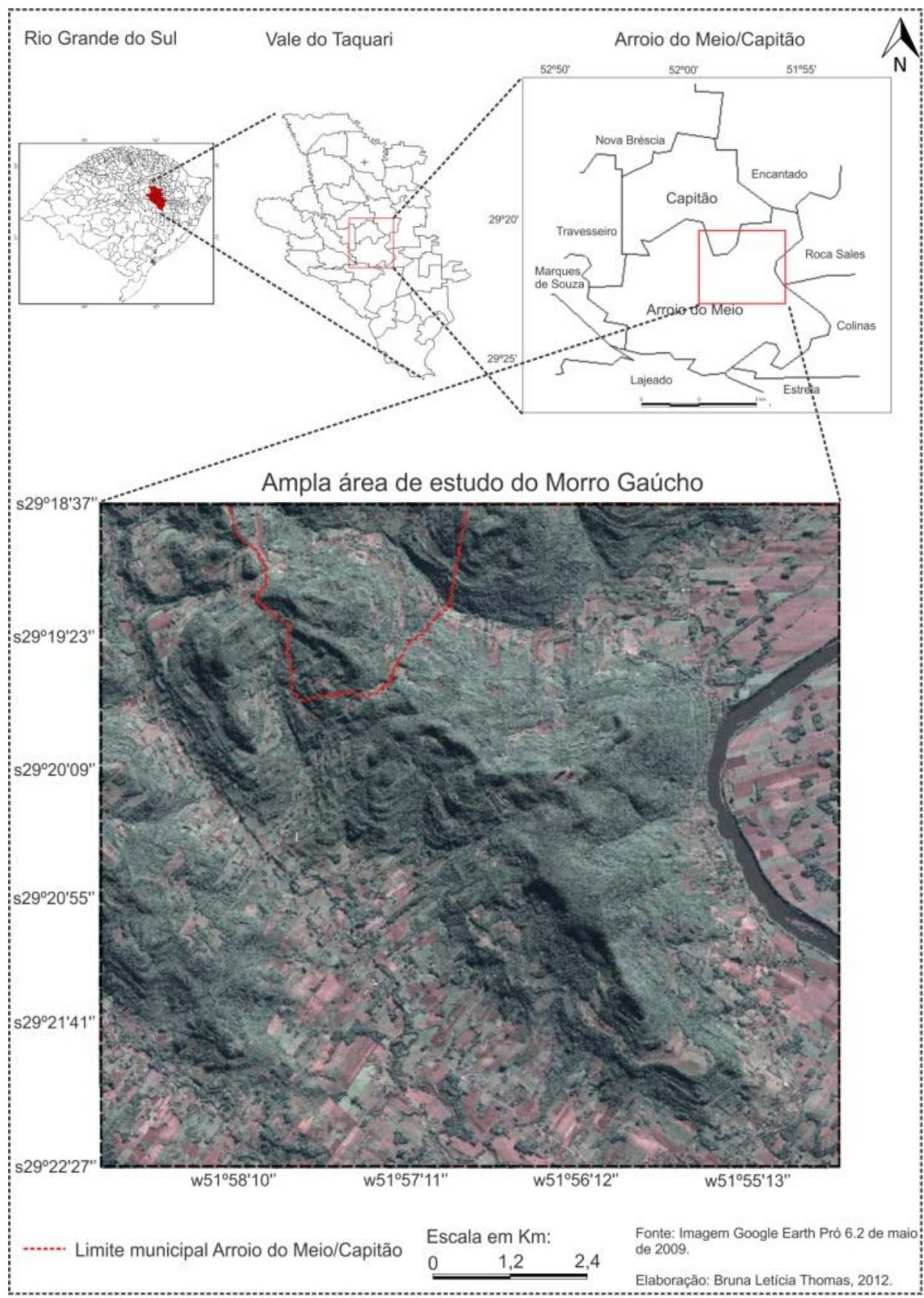

Figura 1: Localização e situação geográfica do Morro Gaúcho.

Geologicamente, o Morro Gaúcho tem sua gênese na Formação Serra Geral, resultante de uma sucessão de derrames de lavas no período da Era Mesozóica. No objeto de estudo encontra-se sua sequência inferior formada por rochas de composição predominantemente básicas, como os basaltos, de textura fina a média e tom acinzentado (INSTITUTO BRASILEIRO DE GEOGRAFIA E ESTATÍSTICA - IBGE, 2003). 
Sob essa formação geológica, entalharam-se as características geomorfológicas. Nos municípios onde se localiza a área de estudo, encontra-se a transição de duas regiões geomorfológicas: da Planície Continental ao Planalto das Araucárias (IBGE, 2003), ou seja, de uma área relativamente plana ao sul para uma área movimentada ao norte. A ocorrência de processos de dissecação fluvial ajudou a esculpir vales encaixados e conjuntos de morros alongados e estreitos, como o Morro Gaúcho e outros situados na região.

Segundo apresentado no Zoneamento Agroclimático do Vale do Taquari (BOTH, s/a), a região onde estão inseridos os municípios de Arroio do Meio e Capitão está enquadrada, de acordo com a classificação internacional climática de Köppen, como zona fundamental temperada úmida, apresentando as variedades climáticas Cfa e Cfb, ou seja, marcada por clima temperado úmido com verão quente e/ou temperado. Os elementos meteorológicos apontam uma precipitação média anual de $1600 \mathrm{~mm}$, sendo estes bem distribuídos ao longo do ano, médias anuais de umidade em $76 \%$ e de temperatura em 18,7 으.

Nestas condições climáticas e geomorfológicas desenvolveu-se o bioma da Mata Atlântica. Das variações desta, ocorre nestes municípios e no Morro Gaúcho a Floresta Estacional Decidual (Tropical Caducifólia), marcada pela grande diversidade florística e faunística. Esta se define por apresentar caducidade em $50 \%$ ou mais dos indivíduos de seu dossel superior devido ao frio (IBGE, 2012).

Alguns autores, como Rempel e Majolo (1999), destacam que o Vale do Taquari apresentava uma cobertura vegetal muito rica, mas que, a partir de 1850, com as imigrações alemãs e italianas, teve-se um acentuado desmatamento. Desta forma, tanto no Vale do Taquari, quanto nos municípios de Arroio do Meio e Capitão, a presença de cobertura vegetal mais significativa restringe-se às áreas situadas em maiores altitudes e declividades acentuadas, onde o uso da terra é dificultado, como é o caso do Morro Gaúcho.

\section{RESULTADOS}

\section{Os impactos ambientais no Morro Gaúcho e por que protegê-lo}

O Morro Gaúcho é um dos pontos mais elevados da porção central do Vale do Taquari, fato que o tornou atrativo turístico devido à bela paisagem da região que se tem de seu topo e à área onde funcionava uma antiga pedreira de exploração de basalto e arredores, que 
atualmente é usada para lazer e prática de esportes, como trilhas, vôos de asa delta e rappel (Figura 2).

Entretanto, apesar do conhecimento sobre este patrimônio natural, o morro vem sofrendo agressões de seus atributos naturais gradativamente. Durante a década de 1960 até meados dos anos 1990, uma pedreira no topo deste realizava a extração de basalto, sendo esse utilizado para as construções das RS 130 e BR 386, importantes rodovias da região e do estado. Segundo Krüger (2008), atualmente, o local sofre com a derrubada da mata nativa, caça e aprisionamento de animais silvestres e extração ilegal de palmito. Contudo é possível destacar também outras agressões ao morro, como a presença de uma unidade de transbordo de resíduos sólidos, espécies exóticas, o turismo irregular, extinções de espécies locais e a fragmentação florestal, entre outros, perceptíveis a partir da realização de trabalhos de campo, leituras de trabalhos científicos, jornais locais e relatos da ONG Ecobé. Na base do Morro Gaúcho situa-se uma unidade de transbordo de resíduos sólidos de origem doméstica. Esta é mais conhecida como "lixão" pelo fato de antigamente ter havido um depósito irregular de resíduos neste lugar. Além disso, a atual área de transbordo não segue alguns padrões técnicos necessários, visto que, por exemplo, às vezes os resíduos encontram-se depositados diretamente em contato com o solo e a céu aberto, ficando expostos às diversas condições climáticas, poluindo ar, água e solo e ameaçando espécies animais e vegetais.

A presença de espécies exóticas como eucaliptos (Eucalyptus sp.), pinus (Pinus sp.) e uvajaponesa (Hovenia dulcis) também é um problema. A ocorrência de eucalipto deve-se principalmente em plantações em pequenas áreas para posterior exploração comercial. Já a ocorrência de pinus e uva-japonesa apresentam-se mais preocupantes, uma vez que ambas são consideradas espécies exóticas invasoras no Rio Grande do Sul (SEMA, 2013), diferentemente do gênero Eucalyptus. Uma vez que invade o ambiente, a espécie invasora altera características próprias do mesmo, como dominância de espécies, teia alimentar, ciclagem de nutrientes e a fisionomia da paisagem. 


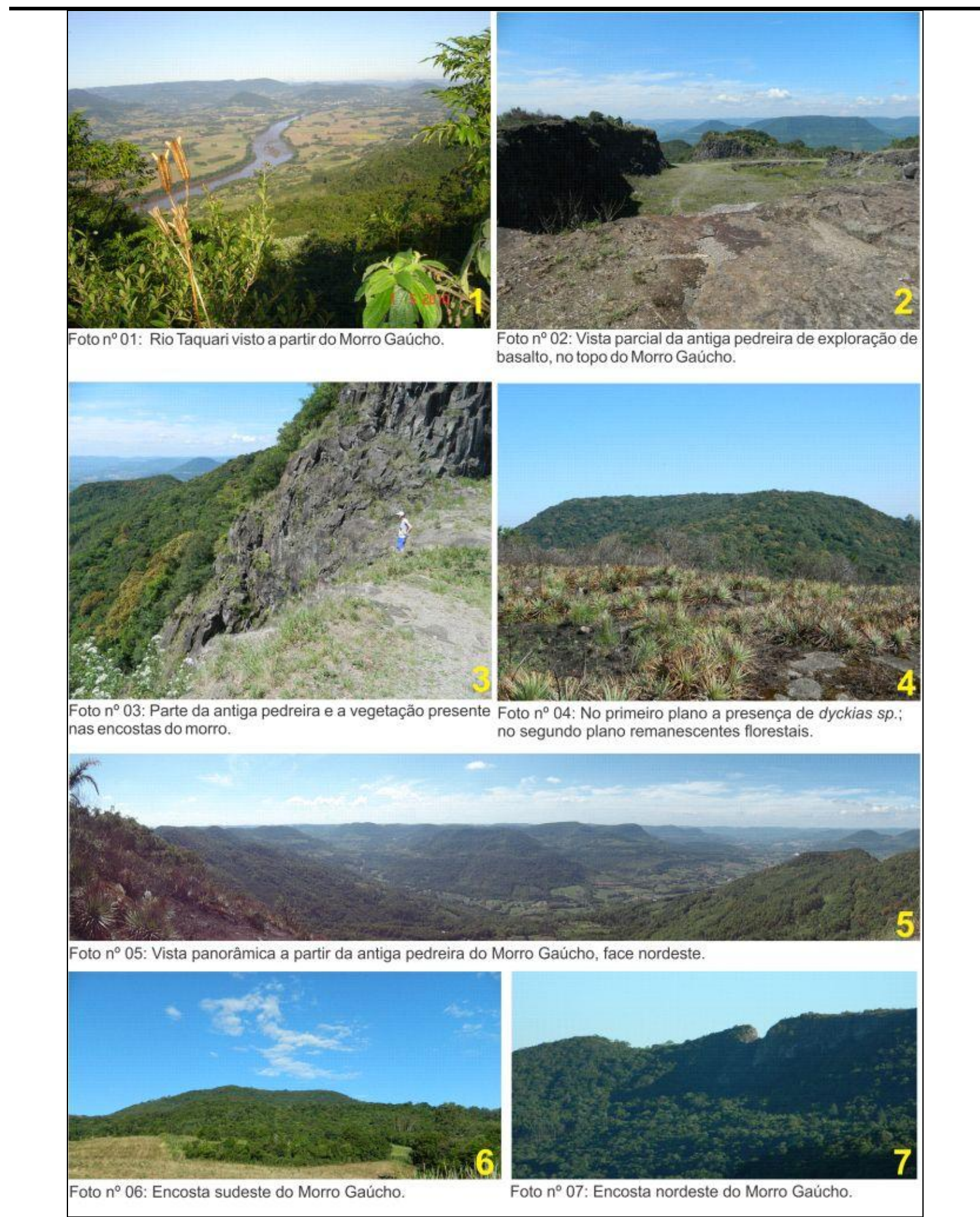

Figura no 02: As belezas do Morro Gaúcho.

Elaboração: THOMAS, B. L., 2012.

Enquanto espécies do gênero Pinus invadem principalmente ambientes abertos, representando menor risco para a área do Morro Gaúcho, $H$. dulcis é caracterizada como invasora agressiva em ecossistemas florestais em climas úmidos (GISP, 2005), representando um risco maior. Além do mais, é considerada invasora na Floresta Estacional Decidual 
(SEMA, 2013) e com registros de invasão em várias cidades da região central do Vale do Taquari, inclusive Arroio do Meio e Capitão (FREITAS; OLIVEIRA, 2012). H. dulcis apresenta alta produção de frutos atrativos à fauna, banco de sementes persistentes no solo e rebrota intensa após o corte, características que possibilitam a sua rápida dispersão e que dificultam o seu controle e erradicação.

Além dessas, o turismo irregular no morro também preocupa, pois os impactos resultantes de trilhas em lugares inapropriados, fogueiras, a presença de lixo, grafias nas rochas, entre outros, são visíveis. Recentemente, em dezembro de 2011, as brasas de uma churrasqueira improvisada alastraram-se devido ao tempo seco e ventos fortes provocando um incêndio numa área de aproximadamente cinco hectares nas redondezas da antiga pedreira do Morro Gaúcho. O fogo que se iniciou no domingo (dia 11), foi combatido pelo Corpo de Bombeiros, moradores e voluntários, sendo contido somente na terça-feira (dia 13), devido à ocorrência de chuvas na região (O ALTO TAQUARI, 2011). Na figura 3 é possível visualizar os impactos ambientais citados.

Todos estes fatores, além de degradarem a paisagem local, ameaçam a biodiversidade presente no Morro Gaúcho, como as espécies vegetais em perigo de extinção no estado do Rio Grande do Sul: Euterpe edulis (palmiteiro) e Parodia haselbergii (cacto) (LEUCHTENBERGER, 2005). A primeira, segundo a autora, apresentou vestígios de estar sendo explorada ilegalmente na área. Já a segunda, encontra-se isolada em um substrato rochoso muito utilizado para a prática de alpinismo, tornando-a ainda mais vulnerável. Além dessas, outras espécies vegetais encontradas no Morro Gaúcho são a Apuleia leiocarpa (grápia), Myrocarpus frondosos (cabreúva) e Ocotea catharinensis (canela-preta), vulneráveis à extinção no estado, assim como a presença de espécies de Ficus organensis (figueira) e Alsophila setosa (xaxim), atualmente protegidas pelo Código Florestal do Rio Grande do Sul Lei Estadual n 9.519/1992 (LEUCHTENBERGER, 2005). 


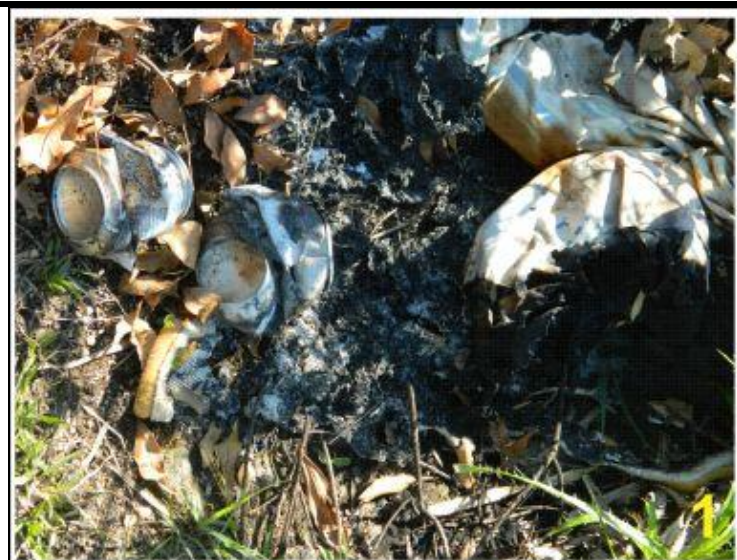

Foto $n^{\circ} 01:$ Impactos do turismo - restos de uma fogueira e latas de alumínio.

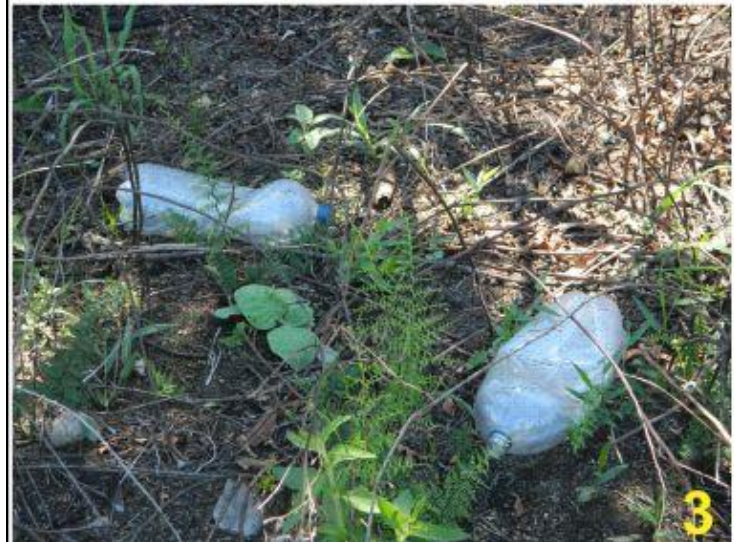

Foto $n^{\circ} 03:$ Impactos do turismo - garrafas PET deixadas naárea.



Foto $n^{\circ}$ 05: Parte de área do topo do Morro Gaúcho atingido pelo incêndio ocorrido em dezembro de 2011.

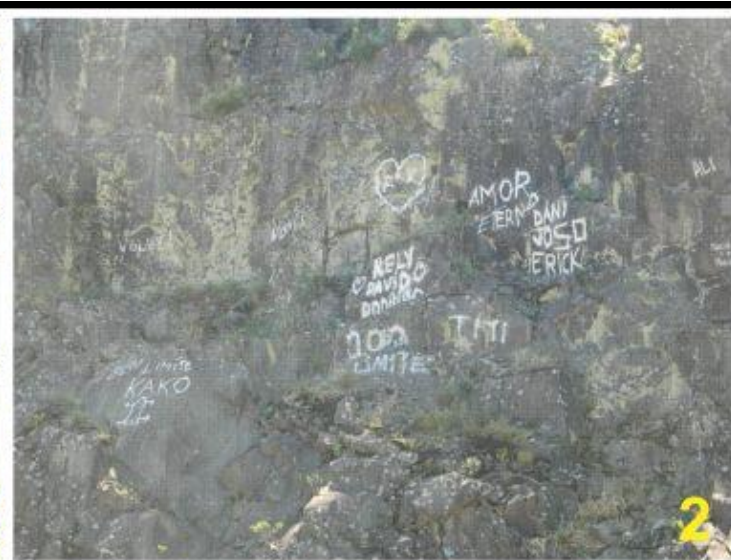

Foto $n^{\circ}$ 02: Impactos do turismo - registro de turistas impresso nas rochas.

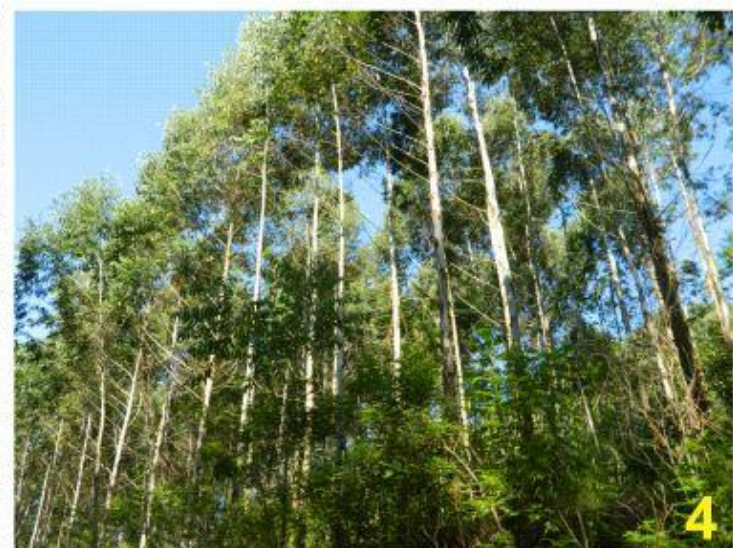

Foto $n^{\circ}$ 04: Plantação de eucalipto na face nordeste do Morro Gaúcho.

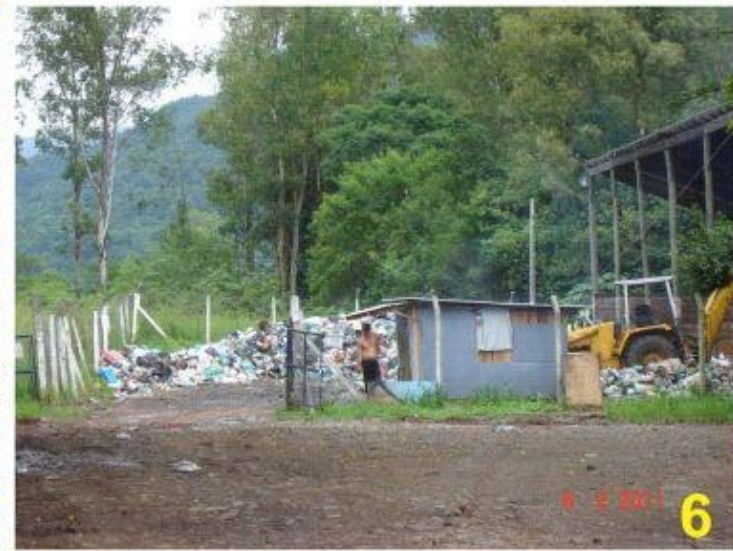

Foto $n^{\circ}$ 06: Unidade de Transbordo localizado Morro Gaúcho. Foto cedida gentilmente por Paulo R. Hamester.

Figura no 03: Impactos ambientais no Morro Gaúcho.

Elaboração: THOMAS, B. L., 2012.

Dentre as espécies da biodiversidade animal já registradas no Morro Gaúcho, a ave Pyroderus scutatus (pavó) encontra-se criticamente em perigo no estado e a Triclaria malachitacea (sabiá-cica), vulnerável de extinção (ECOBÉ, 2004). Já os mamíferos Tamandua tetradactyla (tamanduá-mirim), Nasua nasua (coati), Leopardus trigrinus (gato-do-mato- 
pequeno) e Alouatta fusca (bugio-ruivo) também presentes no local, encontram-se na mesma situação - vulneráveis à extinção (LEUCHTENBERGER, 2005).

Essa vulnerabilidade de espécies vegetais e animais no Morro Gaúcho, além de ser consequência dos outros impactos ambientais já citados, também é decorrente do processo de fragmentação florestal na região, que se deu a partir do uso da terra essencialmente agrícola. A fragmentação de um ecossistema florestal desencadeia uma série de alterações que dificulta a perpetuação das espécies locais, torna o meio mais suscetível a entrada de espécies exóticas, amplia o efeito de borda, diminui a disponibilidade de alimento, reduz o tamanho populacional (diminuindo a possibilidade de encontrar parceiros sexuais e aumentando as perdas por endogamia e deriva genética) e menor disponibilidade de polinizadores e dispersores.

Os efeitos são mais perceptíveis para espécies de níveis tróficos superiores, pois possuem uma necessidade energética maior (ex.: Leopardus guttulus e Cerdocyon thous, ambas presentes no Morro Gaúcho, conforme Leuchtenberger, 2005) Uma vez que uma espécie dessas é extinta localmente, sucedem-se grandes alterações nos níveis tróficos inferiores, abundância e riqueza de espécies no fragmento (TABARELLI; GASCON, 2005). Espécies especialistas, que são muito sensíveis a alterações de hábitat, também tendem a ser muito afetadas pela fragmentação.

Além da ocorrência destes impactos no Morro Gaúcho, há outros fatores que motivam e fortalecem ainda mais a necessidade de sua proteção: o município de Arroio do Meio está integralmente situado na zona de transição da Reserva da Biosfera da Mata Atlântica, e o Morro Gaúcho, quase em sua totalidade, está enquadrado como zona de amortecimento. Já o município de Capitão, em sua maioria é considerado zona de amortecimento e parte em zona de transição (RESERVA DA BIOSFERA DA MATA ATLÂNTICA - RBMA, 2007). A Reserva da Biosfera é uma área protegida de âmbito nacional instituída pela UNESCO (Organização das Nações Unidas para a Educação, a Ciência e a Cultura). Esta se trata de um modelo de gestão integrado, participativo e sustentável dos recursos naturais, visando à preservação da biodiversidade, desenvolvimento de atividades e pesquisas científicas, o monitoramento e a educação ambiental e a melhoria da qualidade de vida das populações (BRASIL, 2000). Já o zoneamento da Reserva, é constituído por três níveis de restrições: a zona núcleo, considerada área de máxima proteção, sendo proibido o corte e exploração da vegetação e as atividades previstas são educação ambiental, ecoturismo e pesquisa científica; a zona de 
amortecimento, onde se admite a exploração das florestas nativas por meio de um sistema de manejo em regime sustentável; e a zona de transição, que não possui um instrumento específico de proteção, mas preza-se pela sustentabilidade de seu uso e ocupação, como a restauração de áreas degradadas (CÔRREA, 1995).

Ainda, o Plano Estratégico Nacional de Áreas Protegidas, PNAP, dispõe como uma de suas diretrizes que os remanescentes dos biomas brasileiros devem ser referência para a criação de UCs (BRASIL, 2006), reforçando a proteção do bioma Mata Atlântica, que é considerado um hot spot devido à sua elevada biodiversidade associada à pressão antrópica, caracterizando-o como em estado crítico de conservação.

Além disso, segundo o Atlas dos Remanescentes da Mata Atlântica, no período entre 2005 e 2008, o município de Arroio do Meio, onde se situa grande parte do morro, teve uma perda de 3 hectares do bioma, possuindo 10\% de Mata Atlântica em seu território (equivalente a 1.511 hectares ou $15 \mathrm{~km}^{2}$ ). Originalmente, $100 \%$ do município era coberto pelo bioma (FUNDAÇÃO SOS MATA ATLÂNTICA/INPE, 2009). Visto que no Morro Gaúcho é onde ainda apresenta-se parte destes remanescentes no município de Arroio do Meio, ressalta-se a importância em sua proteção.

Na esfera municipal, a criação de UCs é expressa no Código do Meio Ambiente do município de Arroio do Meio que prevê como competência do poder público identificar e implantar UCs ou outras áreas protegidas visando à conservação de ecossistemas naturais e recursos ambientais em território municipal (ARROIO DO MEIO, 2000). No município de Capitão, o Código Municipal do Meio Ambiente (Lei Municipal no771/2007) prevê entre os instrumentos da Política Municipal a criação e implantação de UCs. Apesar disso, nenhuma UC foi criada nos municípios até o momento.

\section{CONCLUSÃO}

Tanto as belezas paisagísticas do Morro Gaúcho quanto a degradação ambiental que esse vem sofrendo, confirmam a necessidade de criação de uma UC no local, fato que já vem sendo apontado por estudos/pesquisas referentes ao morro e à Mata Atlântica e presente em legislações ambientais.

Destaca-se que os remanescentes de vegetação ainda abrigam significativa biodiversidade, porém encontram-se seriamente em perigo, como pode ser demonstrado pela ocorrência de 
espécies ameaçadas e protegidas por lei, ressaltando mais ainda a prioridade de conservação da área do Morro Gaúcho.

Deste modo, as necessidades de ações de proteção ambiental ficam evidentes. A criação de uma UC pode garantir que as ameaças que o local vem sofrendo sejam controladas, como a partir do turismo orientado e práticas de educação ambiental, manejo das espécies exóticas invasoras e controle de uso do solo agrícola, melhorias e/ou remoção da unidade de transbordo, estabelecimento de corredores ecológicos, entre outros.

Por fim, vale destacar que a criação de uma UC no Morro Gaúcho deve voltar a ser discutida nos municípios visto sua relevância ambiental e o reconhecimento de sua importância por parte da população local. O estabelecimento de uma área definida geograficamente junto com os seus processos de manejo e gestão podem garantir uma recuperação e proteção ao longo prazo dos atributos ambientais presentes no local.

\section{AGRADECIMENTOS}

À Coordenação de Aperfeiçoamento de Pessoal de Nível Superior (CAPES) pela concessão de bolsa de estudo de mestrado.

\section{REFERÊNCIAS BIBLIOGRÁFICAS}

ARAÚJO, M. A. R. Unidades de Conservação no Brasil: da República à Gestão de Classe Mundial. Belo Horizonte: Editora SEGRAC, 2007.

ARROIO DO MEIO. Lei n. 1.797, de 05 de outubro de 2000. Institui o Código do Meio Ambiente e dá outras providências. PREFEITURA MUNICIPAL DE ARROIO DO MEIO, Arroio do Meio, RS, 05 out. 2000.

BARROS, P. L. P.; BARROS SARTORI, M. da G. Um Brasil de montanhas. Ciência e Natura, Santa Maria, n. 02, 2004, p. 61 - 74 . Disponível em: < http://www.sumarios.org/sites/default/files/pdfs/22-81-1-pb.pdf>. Acesso em: 23 jun. 2012.

BENSUSAN, N. Conservação da biodiversidade em áreas protegidas. Rio de Janeiro: FGV, 2006. 
BOTH, G. C. In: PORTAL do Vale do Taquari. Zoneamento Agroclimático no Vale do Taquari.

Lajeado: $\quad$ UNIVATES, $2006 . \quad$ Disponível em:

<http://www.portaldoagrovt.com.br/agro/meio ambiente/zoneamento agroclimatico no vale do taquari.pdf>. Acesso em: 19 abr. 2010.

BRAGA, R. C. M. S. et al. Valoração ambiental de áreas protegidas para a gestão ambiental. OLAM Ciência e Tecnologia, Rio Claro, n. 01, jan./jun. 2008, p. 68-88. Disponível em: <http://www.periodicos.rc.biblioteca.unesp.br/index.php/olam/article/view/1193>. Acesso em: 24 maio 2011.

BRASIL. Lei Federal n. 12.651, de 25 de maio de 2012. Dispõe sobre a proteção da vegetação nativa; altera as Leis $\mathrm{n}^{\text {os }}$ 6.938, de 31 de agosto de 1981, 9.393, de 19 de dezembro de 1996, e 11.428, de 22 de dezembro de 2006; revoga as Leis $n^{\text {os }} 4.771$, de 15 de setembro de 1965, e 7.754, de 14 de abril de 1989, e a Medida Provisória no⒉166-67, de 24 de agosto de 2001; e dá outras providências. . Presidência da República - Casa Civil, Brasília, DF, 25 maio 2012. Disponível em: $\quad<\quad$ http://www.planalto.gov.br/ccivil 03/Ato20112014/2012/Lei/L12651.htm>. Acesso em: 15 jan. 2013.

. Lei Federal n. 9.985, de 18 de julho de 2000. Regulamenta o art. 225, § 1으, incisos I, II, III e VII da Constituição Federal, institui o Sistema Nacional de Unidades de Conservação da Natureza e dá outras providências. Presidência da República - Casa Civil, Brasília, DF, 18 jul. 2000. Disponível em: <http://www.planalto.gov.br/ccivil 03/leis/19985.htm>. Acesso em: 29 maio 2010.

Decreto Federal n. 5.758, de 13 de abril de 2006. Institui o Plano Estratégico Nacional de Áreas Protegidas - PNAP, seus princípios, diretrizes, objetivos e estratégias, e dá outras providências. Presidência da República - Subchefia para Assuntos Jurídicos, Brasília, DF, 13 abr. 2006. Disponível em: < http://www.planalto.gov.br/ccivil 03/ Ato2004-2006/2006/Decreto/D5758.htm>. Acesso em 18 jan. 2012.

. Resolução n. 303, de 20 de março de 2002. Dispõe sobre parâmetros, definições e limites de áreas de preservação permanente. Ministério do Meio Ambiente, Brasília, DF, 
2002. Disponível em: < http://www.mma.gov.br/port/conama/res/res02/res30302.html>. Acesso em: 23 jun. 2012.

CORRÊA, F. A Reserva da Biosfera da Mata Atlântica: roteiro para o entendimento de seus objetivos e seu sistema de gestão. São Paulo: UNESCO, 1995. Disponível em: <http://www.rbma.org.br/rbma/pdf/Caderno 02.pdf> Acesso em: 25 fev. 2014.

INSTITUTO BRASILEIRO DE GEOGRAFIA E ESTATÍSTICA. Diretoria de Geociências. Carta Geológica Caxias do Sul: Escala: 1: 250. 000. Rio de Janeiro, 2003.

INSTITUTO BRASILEIRO DE GEOGRAFIA E ESTATÍSTICA. Diretoria de Geociências. Carta Geomorfológica Caxias do Sul: Escala: 1: 250. 000. Rio de Janeiro, 2003.

DRUMMOND, J. A.; FRANCO, J. L. de A.; NINIS, A. B. O estado das áreas protegidas do Brasil - 2005. Brasília: [s.n.], 2006.

DUDLEY, N. (Ed.). Directrices para la aplicación de las categorías de gestión de áreas protegidas. Suíça: UICN, 2008.

ECOBÉ. Levantamento e mapeamento biótico no Morro Gaúcho, Arroio do Meio, RS, Brasil: Proposta de criação de uma Unidade de Conservação. Arroio do Meio, 2004.

FUNDAÇÃO ESTADUAL DE PROTEÇÃO AMBIENTAL HENRIQUE LUIZ ROESSLER/RS - Fundação Estadual de Proteção Ambiental Henrique Luiz Roesler. Porto Alegre, 2002. Disponível em: <http://www.fepam.rs.gov.br/programas/kfw.asp> Acesso: 07 maio 2012.

FUNDAÇÃO SOS MATA ATLÂNTICA/INSTITUTO NACIONAL DE PESQUISAS ESPACIAIS. Atlas dos Remanescentes Florestais da Mata Atlântica: período 2005 - 2008, relatório parcial. São Paulo, 2009.

FUNDAÇÃO ZOOBOTÂNICA RS. Lista final das espécies da flora ameaçadas - RS. Porto Alegre, 2003.

GISP. América do Sul Invadida: a crescente ameaça de espécies exóticas invasoras. Rio de Janeiro: GISP - Programa Global de Espécies Invasoras, 2005. 80p. 
GURGEL, H. C. et al. Unidades de conservação e o falso dilema entre conservação e desenvolvimento. In: MEDEIROS, R.; ARAÚJO, F. F. S. (Org.). Dez anos do Sistema Nacional de Unidades de Conservação da Natureza: lições do passado, realizações presentes e perspectivas para o futuro. Brasília: MMA, 2011, p. 37 - 57.

IBGE. Manual Técnico da Vegetação Brasileira. Rio de Janeiro, Brasil. 2012. 271 p.

KRÜGER, A. Ecoturismo e sustentabilidade no Vale do Taquari: possibilidades a partir do estudo de caso no Morro Gaúcho em Arroio do Meio. 2008. 170 f. Dissertação (Mestrado em Ambiente e Desenvolvimento) - Centro Universitário Univates, Lajeado, 2008.

LEUCHTENBERGER, C. Caracterização e diagnóstico ambiental da região do Morro Gaúcho, Vale do Taquari, com vistas à implantação de uma unidade de conservação. 2005. 76 f. Trabalho de Conclusão de Curso (Graduação em Ciências Biológicas Licenciatura) Universidade do Vale dos Sinos, São Leopoldo, 2005.

MEDEIROS, R. Evolução das tipologias e categorias de Áreas Protegidas no Brasil. Ambiente \& Sociedade, Campinas, n. 1, jan./jun., 2006, p. 41-64. Disponível em: <http://www.scielo.br/pdf/asoc/v9n1/a03v9n1.pdf>. Acesso em: 17 abr. 2011.

MEDEIROS, R.; YOUNG, C. E. F. Contribuição das unidades de conservação brasileiras para a economia nacional: Relatório Final. Brasília: UNEP-WCMC, 120 p. Disponível em: <http://www.mma.gov.br/estruturas/sbf2008 dap/ publicacao/149 publicacao080620111 00539.pdf >. Acesso em: 01 jun. 2012.

O ALTO TAQUARI. Morro Gaúcho em chamas. Jornal O Alto Taquari, Arroio do Meio, p. 11, 16 dez. 2011.

FREITAS, E. M.; OLIVEIRA, T. A. Uva-japonesa - uma ameaça à diversidade das formações florestais regionais. Jornal O Informativo do Vale, Lajeado, 17 set. 2012.

PELLIN, A. et al. Compensação ambiental como fonte de recursos para unidades de conservação: situação atual e aspectos polêmicos. OLAM Ciência e Tecnologia, Rio Claro, n. 02, dez. 2007, p. 171-186. Disponível em: <http://www.periodicos.rc.biblioteca.unesp.br/index.php/olam/article/view/887>. Acesso em: 02 jun. 2012. 
REMPEL, C.; MAJOLO, M. A. Levantamento ambiental do município de Arroio do Meio - Vale do Taquari. Acta Scientiae, Canoas, n. 02, jul/dez. 1999, p. 29 - 38. Disponível em: < http://www.sumarios.org/sites/default/files/pdfs/ilovepdf.com split 4 0.pdf>. Acesso em: 14 abr. 2013.

RIO GRANDE DO SUL. Decreto Estadual n. 41.672, de 11 de junho de 2002. Declara as Espécies da Fauna Silvestre Ameaçadas de Extinção no Estado do Rio Grande do Sul e dá outras providências. Palácio do Piratini, Porto Alegre, RS, 11 jun. 2002. Disponível em: < http://www.fzb.rs.gov.br/downloads/fauna ameacada.pdf>. Acesso em: 18 abr. 2013.

. Lei Estadual n. 9.519, de 21 de janeiro de 1992. Institui o Código Florestal do Estado do Rio Grande do Sul e dá outras providências. Assembleia Legislativa do estado do Rio

Grande do Sul, Porto Alegre, RS, 21 jan. 1992. Disponível em: < http://www.al.rs.gov.br/Legis/M010/M0100099.ASP?Hid Tipo=TEXTO\&Hid TodasNormas= 16489\&hTexto=\&Hid IDNorma=16489>. Acesso em: 20 jun. 2012.

SEMA. Portaria ${ }^{\circ} 79$ de 31 de outubro de 2013. Secretaria de Estado de Meio Ambiente do Rio Grande do Sul. Porto Alegre, RS, 31 out. 2013. Disponível em: < http://institutohorus.org.br/download/marcos legais/Portaria\%20SEMA\%20RS\%2079\%20\%202013\%20Lista\%20invasoras.pdf>. Acesso em: 26 jan. 2014.

TABARELLI, M.; GASCON, C. Lições da pesquisa sobre fragmentação: aperfeiçoando políticas e diretrizes de manejo para a conservação da biodiversidade. Megadiversidade, Belo Horizonte, vol. 1, n. 1, jul. 2005. Disponível em: http://www.conservacao.org/publicacoes/files/24 Tabarelli Gascon.pdf. Acesso em: 03 fev. 2013.

Artigo recebido em 08/01/2014.

Artigo aceito em 13/03/2014. 